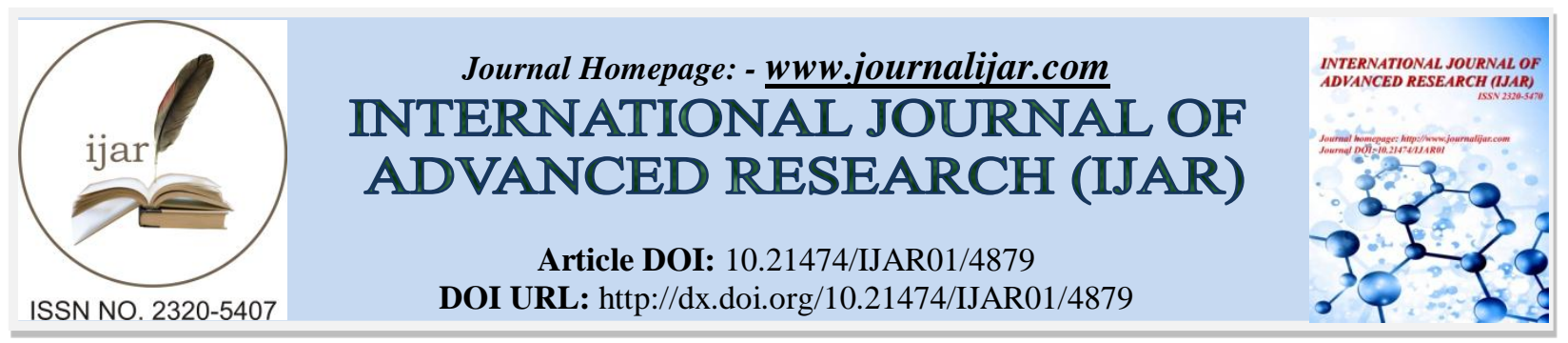

RESEARCH ARTICLE

\title{
ALTERNATIVE TECHNIQUE OF PANCREATICOGASTROSTOMY AFTER PANCREATICODUODENECTOMY A REGIONAL CANCER CENTRE STUDY.
}

\author{
Mohit Sharma ${ }^{1}$, Ketul puj ${ }^{2}$, Hemkant verma ${ }^{2}$ and Shashank J. Pandya ${ }^{3}$. \\ 1. Associate Professor, Department of Surgical Oncology Gujarat Cancer And Research Institute (G.C.R.I.), \\ Ahmedabad. \\ 2. Resident Doctor, Department of Surgical Oncology Gujarat Cancer And Research Institute (G.C.R.I.), \\ Ahmedabad. \\ 3. Professor, Department of Surgical Oncology Gujarat Cancer And Research Institute (G.C.R.I.), Ahmedabad.
}

\section{Manuscript Info}

Manuscript History

Received: 18 May 2017

Final Accepted: 20 June 2017

Published: July 2017

Key words:-

Pancreaticogastrostomy,Pancreaticoduod enectomy,Pancreatic Fistula.

\section{Abstract}

Background; Post operative pancreatic fistula (POPF) is a major concern after pancreaiticoduodenectomy(PD). In this sudy we presented our experience of pancreaticogastrostomy(PG) with our technique after pancreaicoduodenecomy. This technique is simple and effective in reducing chances of post operative pancreatic fistula(POPF).

Material And Method: We performed PG with this alternative technique on 36 patients of pancreatic cancers operated in Gujarat Cancer And Research Institute between January 2014 to December 2016. We described a different technique of pancreaticogastrostomy without anterior gastroatomy.PG was done by taking multiple interrupted sutures between pancreatic parenchyma and posterior wall of stomach after delivering pancreatic remanent through posterior wall of stomach.

Results: Out of 36 patients 18(50\%) were of pancreatic head cancers. There was no perioperative mortality in this study.No patient developed significant POPF.

Conclusion: Our technique of PG is simple,easy to perform and effective in controlling life threatening complications such as POPF.

Copy Right, IJAR, 2017,. All rights reserved.

\section{Introduction:-}

Pancreaticoduodenectomy is the most commonly performed surgery for treatment of pancreatic cancers.POPF is the most lifethreatening complication after PD.The rate of POPF is in the range of 5\%-35\%(1) .Leakage from pancreaticoenteric anastomosis is the most common cause of $\operatorname{POPF}(2,3$,$) .Important contributory factors in$ occurance of POPF are consistancy of pancreas, diameter of pancreatic duct and expertise of surgeon in performing pancreaticoenteric anastomosis. Some reports have shown PG o be superior to $\mathrm{PJ}(4,5,6$,$) but majority has no$ consensus regarding best technique $(7,8)$. Since its evolution various modifications( such as binding,transfixing), has been done in technique of PG by surgeons to improve outcomes $(9,10,11)$.In most of centers in world pancreaticojejunostomy $(\mathrm{PJ})$ is the standard procedure to achieve pancreaticoenteric integrity following PD.PJ has its own limitations in form of pancreatic duct diameter,consistency of pancreas.

Corresponding Author:- Mohit Sharma.

Address:- Associate Professor, Department of Surgical Oncology Gujarat Cancer And Research Institute (G.C.R.I.), Ahmedabad. 
We presented an alternative technique of PG using interrupted absorbable sutures between full thickness of posterior wall of stomach and pancreatic substance.Pancreatic duct diameter and consistency of pancreas are not limiting factors in this technique.Technique is simple and easy to perform.It can be applied in all cases irrespective of pancreatic duct diameter and consistency of pancreas with satisfactory results in form of control of POPF.

\section{Material and Methods:-}

It is a prospective observational study done at Gujarat Cancer And Research Institute(GCRI) Ahmedabad.We studied 36 cases of pancreatic cancers who underwent PD from January 2014 to December2016.In all the cases PG was done by this alternate technique using multiple interrupted sutures between pancreatic parenchyma and posterior wall stomach. All the surgeries were done by same method and anastomotic technique by different surgeons.

\section{Surgical Technique:-}

In all the patients classical PD was performed irrespective to the site of primary disease.Removal of gastric antrum facilitates easy delivery of pancreatic remanent through posterior wall of stomach without performing anterior gastrostomy.

After removal of primary tumor complete hemostasis is achieved. Particular attention is paid on pancreatic remanent.Hemostasis is achieved on pancreatic stump with bipolar electrocautary and hemoststic sutures.Some times bleeding from cut end pancreas may be cause of hemetemesis.

Pancreatic remanent is mobilized for $3-4 \mathrm{~cm}$ length from underlying spleenic vein with help of bipolar electrocautary. All the draining vessels into pancreas are ligated.Adequate mobilization of pancreas is one of the determining step for successful surgical outcome(Figure1)

Four full thickness sutures are taken from cut end of pancreatic remanent at 120 'clock, 3o'clock,6o'clock and 90 'clock position. These sutures work as holding sutures and helps in smooth delivery of pancreatic remanent through opening in poster wall of stomach.Equal traction on all the holding sutures facilitates easy delivery of pancreatic remanent.

After preparation of pancreatic stump next step is the delivery of pancreatic stump through posterior wall of stomach.For this small transverse cut is placed on posterior wall of stomach almost 5-6 cm away from cut end of stomach.It can be done by putting index finger of left hand through cut end of stomach remanent on posterior wall stomach.Posterior wall of stomach is cut open on prominent index finger with help of electrocautary.Size of transverse cut should be such that pancreatic remanent should snugly come out from it,without keeping any space.As stomach wall is stretchable,opening in posterior wall of stomach should be three fourth of the diameter of pancreatic remanent.

Now pancreatic remanent is delivered through the posterior wall of stomach with help of equal traction on holding sutures passed through pancreas and counter traction on posterior wall of stomach.It is the most important step in this technique.Almost 2c.m pancreatic stump should come into stomach.

As classical PD was done in all the cases there was adequate space to deliver pancreatic stump through posterior wall stomach, so no need of anterior gastrostomy.

In properly done PG $2 \mathrm{c} . \mathrm{m}$ pancreatic remanent should protrude through posterior wall stomach without any gap between pancreatic capsule and opening in posterior wall stomach(Figure2)

Now multiple interrupted sutures are taken between pancreatic parenchyma and posterior wall stomach with help of 3-0 PDS(Poly dioxanone) on round body needle at equal distance to keep pancreatic stump in place.

Open end of stomach is used for subsequent gastrojejunostomy after doing end to side hepaticojejunostomy.Ryle's tube is placed near PG to decompress stomach.Feeding jejunostomy is made as per routine protocol.Two abdominam drains were kept one in subhepatic region and another in pelvis.Abdominal drain fluid amylase and serum amylase levels were done on post operative day 3 and 5 to detect any post operative pancreatic leak. 
International study group on pancreatic fistula classification was used to describe type of POPF.

\section{Results:-}

Total 36 patients underwent PD with PG. There were 27 males and 9 females.Mean age was 45 year.Youngest patient was 14 years old boy with pancreatic head neuroendocrine tumor and oldest was 70 years old female with periampullary carcinoma.Out of 36 patients $18(50 \%)$ patient had pancreatic head cancers, $12(33.3 \%)$ patient had periampullary cancers and $6(16.6 \%)$ patient were lower common bile duct cancers.In the present series no mortality was noted.Complications occurred in $12(33.3 \%)$ patients. Wound infection was most common (33.3\%)complication as most of the patients were stented in this study.Next most common complication was delayed gastric emptying which was noted in $8(22.2 \%)$ patients.Delayed gastric emptying was defined as not able to tolerate oral feeds till tenth postoperative day.Pancreatic leak occurred in 2(5.5\%) patients which were of type A and B type.There was no major POPF noted .Both pancreatic leaks were confirmed by biochemical analysis of drain fluid amylase and radiologically with computerized axial tomography(CAT) scan.Both patients were stable clinically and were managed conservatively without any invasive procedure.Minor biliary leak was also noted in 2(5.5\%) patients which was also managed conservatively.In the present study $3(8.3 \%)$ patients developed hematemesis during post operative course.On upper gastrointestinal endoscopy all three had severe erosive gastritis. All three patients were managed conservatively with intravenous proton pump inhibitors, and oral sucralfate administration.Median hospital say was 12 days(range 9 to 28 days).On final histopathological examination 29 (80.5\%) patients had adenocarcinoma,1(2.77\%) patient had neuroendocrine tumor and 6(16.6\%) were of lower commom bile duct cholangiocarcinoma.

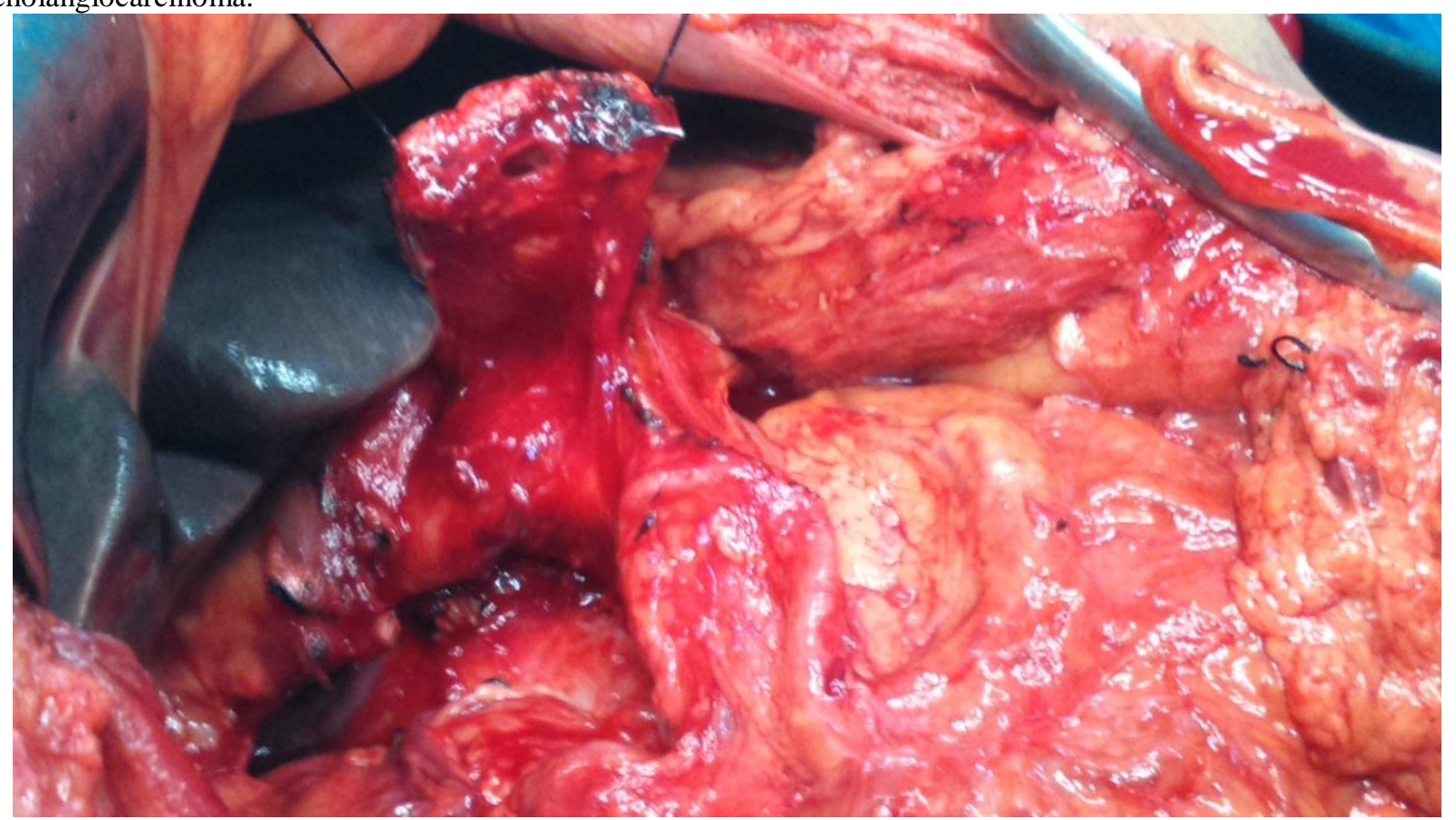

Figure 1:- Pancreatic remanent mobilized adequately from underlying spleenic vessels and lifted with help of holding sutures 


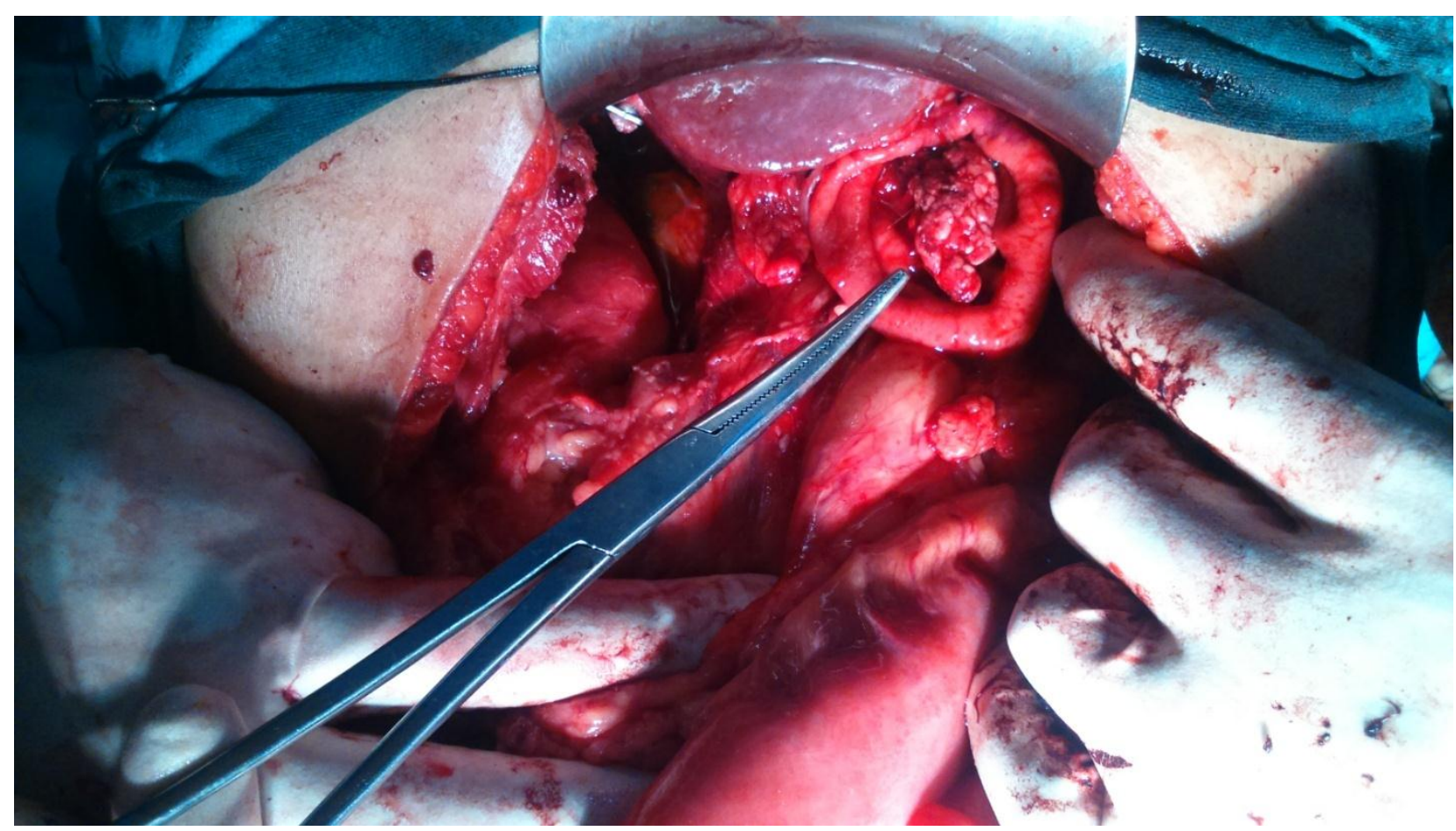

Figure 2:- Final position of pancreatic remanent in stomach after passing through posterior gastrostomy

\section{Discussion:-}

Pancreaticoenteric anastomosis failure is the major reason of morbidity and mortality following PD.PG and PJ are two most common type of pancreaticoenteric anastomotic techniques. Several modifications have been developed in these techniques such as end to end or end to side anastomosis,invagination or duct to mucosa anastomosis, binding PJ,pancreatic duct stenting methods etc.(12,13). Waugh performed first PG on human in 1944.(14)

Optimal method to restore pancreatic digestive continuity is controversial.Three randomized control trials(15) and four meta anlysis $(16,17,18)$ reported lower rates of post operative pancreatic fistula associated with PG then PJ.

In pancreaticoenteric anastomosis an attachment between two different organs is made. Pancreas is solid retroperitoneal fixed organ while jejunum is tubular hollow and mobile structure. So there are more chances of anastomotic disruption when anastomosis is made between these two organs as done in PJ.On the contrary stomach has rich blood supply,lies in close proximity to pancreas so there are high chances of stability in pancreaticogastric anastomosis. Additionaly acid rich environmentof stomach causes enzymatic inactivation of pancreatic secretions.

In this study we reported new technique of PG with use of multiple interrupted sutures between posterior wall of stomach and pancreatic substance.The pancreatic remanent should snugly fit in opening made on posterior wall of stomach without having any gap.

\section{This method has following advantages:-}

- It is simple and easy to perform. The median time taken o perform PG is 15 minutes

- Pancreatic duct diameter and pancreatic consistency are not limiting factors because pancreatic remanent lies in natural tension free position

- Entire cut end of pancreas remains in the stomach cavity there are no chances of collecting pancreatic secretions out side stomach

- No special surgical expertise is required to perform this type of PG.In the present study PG was done by trainee surgical residents as well as senior surgeons with almost same results. 
The technical and physiological advantages and disadvantages of PG has been discussed in several studies(19,20). Post operative pancreatic leak which occur following PG are comparatively less fatal because great vessels are not in close proximity

Continuous nasogastric suction is useful in presence of POPF after PG to decompress stomach.Invasive drainage procedures are not required in most of cases.

Long term outcomes of pancreatic exocrine and endocrine functions should be considered according to type of pancreaticoenteric anastomosis.PG has its own theoretical disadvantages in terms of metabolic derangements,pancreatic exocrine insufficiencies due to gastric reflux in pancreatic duct(21).Large multicentric randomized controlled trials should be done to determine appropriate anastomotic technique for individual.

\section{Conclusion:-}

This is a simple alternative technique of PG with good results. This is a effective reconstructive procedure for soft and fragile pancreas without any learning curve.

\section{Conflicts Of Interest:-}

No potential conflict of interest relevant to this article was reported.

\section{References:-}

1. Reid-Lombardo KM, Farnell MB, Crippa S, Barnett M, Maupin G, Bassi C, et al. Pancreatic anastomotic leakage after pancreaticoduodenectomy in 1507 patients: a report from the Pancreatic Anastomotic Leak Study Group. J Gastrointest Surg 2007;11:1451-1458.

2. Yeo CJ, Cameron JL, Sohn TA, Lillemoe KD, Pitt HA, Talamini MA, et al. Six hundred fifty consecutive pancreaticoduodenectomies in the 1990s: pathology, complications, and outcomes. Ann Surg 1997;226:248257; discussion 257-260.

3. Veillette G, Dominguez I, Ferrone C, Thayer SP, McGrath D, Warshaw AL, et al. Implications and management of pancreatic fistulas following pancreaticoduodenectomy: theMassachusetts General Hospital experience. Arch Surg 2008;143:476-481.

4. Fang WL, Shyr YM, Su CH, Chen TH,Wu CW, Lui WY. Comparison between pancreaticojejunostomy and pancreaticogastrostomy after pancreaticoduodenectomy. J Formos Med Assoc 2007; 106:717-27.

5. Kim JH, Yoo BM, Kim JH, Kim WH. Which method should we select for pancreatic anastomosis after pancreaticoduodenectomy? World J Surg 2009;33: 326-32.

6. Zhu F, Wang M, Wang X, Tian R, Shi C, Xu M, et al. Modified technique of pancreaticogastrostomy for soft pancreas with two continuous hemstitch sutures: a single-center prospective study. J Gastrointest Surg 2013;17:1306-11.

7. Yang SH, Dou KF, Sharma N, Song WJ. The methods of reconstruction of pancreatic digestive continuity after pancreaticoduodenectomy: a meta-analysis of randomized controlled trials. World J Surg 2011;35:2290-7.

8. Nakao A, Fujii T, Sugimoto H, Kaneko T, Takeda S, Inoue S, et al. Is pancreaticogastrostomy safer than pancreaticojejunostomy? J Hepatobiliary Pancreat Surg 2006;13:202-6.

9. Payne RF, Pain JA. Duct-to-mucosa pancreaticogastrostomy is a safe anastomosis following pancreaticoduodenectomy. Br J Surg 2006;93:73-7.

10. Murakami Y, Uemura K, Hayashidani Y, Sudo T, Hashimoto Y, Nakagawa N, et al. No mortality after 150 consecutive pancreatoduodenctomies with duct-to-mucosa pancreaticogastrostomy. J Surg Oncol 2008;97:2059.

11. Bassi C, Butturini G, Salvia R, Crippa S, Falconi M, Pederzoli P. Open pancreaticogastrostomy after pancreaticoduodenectomy: a pilot study. J Gastrointest Surg 2006;10:1072-80.

12. Chen HW, Lai EC, Su SY, Cai YF, Zhen ZJ, Lau WY. Modified technique of pancreaticojejunal anastomosis with invagination following pancreaticoduodenectomy: a cohort study. World J Surg 2008;32:2695-700.

13. Tran K, Van Eijck C, Di Carlo V, Hop WC, Zerbi A, Balzano G, et al. Occlusion of the pancreatic duct versus pancreaticojejunostomy: a prospective randomized trial. Ann Surg 2002;236:422-8.

14. Waugh JM, Clagett OT. Resection of the duodenum and head of the pancreas for carcinoma. Surgery. 1946;20:224-32.

15. Wellner HF, Sick O, Olschewski M, Adam U, Hopt UT, Keck T. Randomized controlled single-centre trial comparing pancreatogastrostomy versus pancreaticojejunostomy after partial pancreatoduodenectomy. J Gastrointest Surg 2012;16:1686-1695. 
16. McKay A, Mackenzie S, Sutherland FR, Bathe OF, Doig C, Dort J, et al. Meta-analysis of pancreaticojejunostomy versus pancreaticogastrostomy reconstruction after pancreaticoduodenectomy. $\mathrm{Br} \mathrm{J}$ Surg 2006;93:929-936.

17. Wente MN, Shrikhande SV, Müller MW, Diener MK, Seiler CM, Friess H, et al. Pancreaticojejunostomy versus pancreaticogastrostomy: systematic review and meta-analysis. Am J Surg 2007;193:171-183.

18. Liu FB, Chen JM, Geng W, Xie SX, Zhao YJ, Yu LQ, et al. Pancreaticogastrostomy is associated with significantly less pancreatic fistula than pancreaticojejunostomy reconstruction after pancreaticoduodenectomy: a meta-analysis of seven randomized controlled trials. HPB 2015;17:123-130.

19. Arnaud JP, Tuech JJ, Cervi C, Bergamaschi R. Pancreaticogastrostomy compared with pancreaticojejunostomy after pancreaticoduodenectomy. Eur J Surg 1999; 165:357-362.

20. Bartsch DK, Langer P, Kanngiesser V, Fendrich V, Dietzel K: A simple and safe anastomosis for pancreatogastrostomy using one binding purse-string and two transfixing mattress sutures. Int J Surg Oncol, 2012:718637.

21. Jang JY, Kim SW, Park SJ, Park YH. Comparison of the functional outcome after pylorus-preserving pancreatoduodenectomy: pancreatogastrostomy and pancreatojejunostomy. World J Surg 2002;26:366-71. 